\title{
Traditional Practices for Mother and Infant Care in North Cyprus: What is Known, and What is Being Applied?
}

\author{
Dilay Necipoğlu (D, Belkıs Karataș Aktaș (1) \\ Near East University School of Nursing, Nicosia, Cyprus \\ ORCID IDs of the authors: D.N. 0000-000I-82I3-5854; B.K.A. 0000-0002-5468-4I08.
}

\begin{abstract}
Cite this article as: Necipoğlu D, Karataș Aktaș B. Traditional Practices for Mother and Infant Care in North Cyprus: What is Known, and What is Being Applied? Cyprus J Med Sci 2018; 3(3): 137-43.
\end{abstract}

BACKGROUND/AIMS

We conducted this study to determine traditional methods that women living in the center of Nicosia are aware of and apply in the maternal and infant care in the postpartum period.

\section{MATERIALS AND METHODS}

The study had a descriptive design. According to the results of the 2011 census, the universe of research consisted of 11,879 married women from the center of Nicosia. Our study included a total of 372 women. A questionnaire developed by researchers was used. The data were collected between September I and December 31, 2015, by the researcher visiting homes and interviewing women personally. A written approval from the Ethics Committee was obtained.

\section{RESULTS}

The study showed that $91.94 \%$ of the women applied the traditional methods on themselves and $92.2 \%$ on their babies in the postpartum period. It was also identified that there was a statistically significant difference $(p<0.05)$ between the application of any kind of traditional practices on themselves depending on the age group, their educational status, and health status. The level of significance was set at 0.05

\section{CONCLUSION}

It was determined that the majority of women applied traditional practices in the maternal and infant care in the postpartum period.

Keywords: Postpartum period, traditional practices, nursing

\section{INTRODUCTION}

Finding their roots in tradition and being passed on from one generation to another, traditional methods are approaches that are main in almost every part of the world at different frequencies. On the other hand, traditional health practices are the medical practices of the society in relation to that society's beliefs, traditions, values, and culture $(\mathrm{I}, 2)$. The prevalence of traditional postpartum practices in all societies is noteworthy $(3,4)$. Some traditions, customs, and beliefs about birth and reproduction are also seen in the life of the Turks $(2,3,5,6)$.

The impact of traditional practices on health can be positive, whereas it can occasionally also reach negative dimensions, threatening life (7). Malpractice during the postpartum period can prolong the healing process of the mother and the baby, as well as prevent the effective treatment; and they can also result in disability, illness, and even death $(4,8,9)$. The application of harmful traditional methods with the belief of albasması (a local belief suggesting that the woman can show the symptoms of febrility, somniloquy, and hallucination because of the influence of bad spirits in the postpartum period) may cause a puerperal woman to get worse by delaying the treatment. The traditional method of swaddling the baby may be uncomfortable, lead to restlessness, and leads predispositions to hip dislocation $(\mathrm{I}, 2)$.

Reflecting the cultural beliefs and practices of the individuals, nurses should support beneficial practices and include them in their care, and they should be cautious when it comes to preventing adverse health effects of harmful practices (6, 10$)$.

This study was presented at the Ist International and 2nd National Obstetrics and Gynecology and Maternal And Infant Care Congresses. 6-7 October, 2016. 
Nurses whose role is to improve the health-related behavior of the community should be educated about the cultural factors that improve the health behaviors and reject the wrong practices (IO).

The aim of this study was to determine the awareness and application of traditional methods among women and infants during the postpartum period in the center of Nicosia. We investigated the knowledge of traditional methods in the postpartum period that will improve the awareness and enhance health services for the families and public.

\section{Study Questions}

Women living in the center of Nicosia

I. What is the knowledge level about the traditional methods with regard to maternal and infant care in the postpartum period?

2. Is there any difference between descriptive characteristics and knowledge of the traditional methods?

\section{MATERIALS AND METHODS}

\section{Study Design}

The study has a descriptive design.

\section{Sample Selection}

According to the results of the 20ll census, there was a total of II,879 residing married women in the center of Nicosia. Our study included 372 women. Twenty-three neighborhoods were stratified in order to be able to represent the married women living in the center of Nicosia in the study and to ensure a homogeneous distribution. According to the influent layer weight, a minimum of I and maximum of 79 people were sampled in this area. Then, the women included in the sample according to the stratum size from neighborhoods were selected by the random sampling method. Samples were taken from women, who were married, have at least one child and knew Turkish. There were no refusals to participate in the study.

\section{Study Tools}

A questionnaire was developed by the researchers based on the literature, and it was used as a data collection tool in this study $(1,7,10)$. The questionnaire consisted of two parts. In the first part, questions were prepared to determine the socio-demographic and descriptive characteristics of women, and in the second part, the aim was to identify the traditional practices of women regarding the maternal and infant care.

\section{Statistical Analysis}

The questionnaire was collected between September I and December 3I, 2015, by the researcher who visited homes and interviewed the women personally. A statistical analysis of the obtained data was performed using the Statistical Package for Social Sciences version 2 I.0 (IBM Corp.; Armonk, NY, USA) program, and the number and percentage distributions were used in addition to the chi-squared tests.

\section{Pilot Study}

A pilot study was performed on 37 women in a neighborhood outside the center of Nicosia. After the pilot study, a revision was not necessary. However, the women who participated in the pilot study were not included in the main sample.

\section{Ethical Considerations}

Ethical approval was obtained from the Research Ethics Committee of the Near East University, and before the data collection, a written informed consent was also obtained, and the researchers explained the study aims. An additional written permission was obtained from the Nicosia Local Government.

\section{RESULTS}

A total of $37.63 \%$ of the survey participants were in the age group between 40 and 49 years, $43.5 \%$ were high school gradvates, $60.75 \%$ had a job, and $98.92 \%$ had a nuclear-type family. Most of the participants responded that they perceived their economic situation level as moderate (91.4\%). Majority of respondents had health insurance ( $81.8 \%$ ). In the postpartum period, $91.94 \%$ of the women reported that they applied at least one traditional practice on themselves and $92.2 \%$ on their babies.

TABLE I. The data of women who apply a traditional method on themselves, according to descriptive characteristics ( $\mathrm{n}: 372$ )

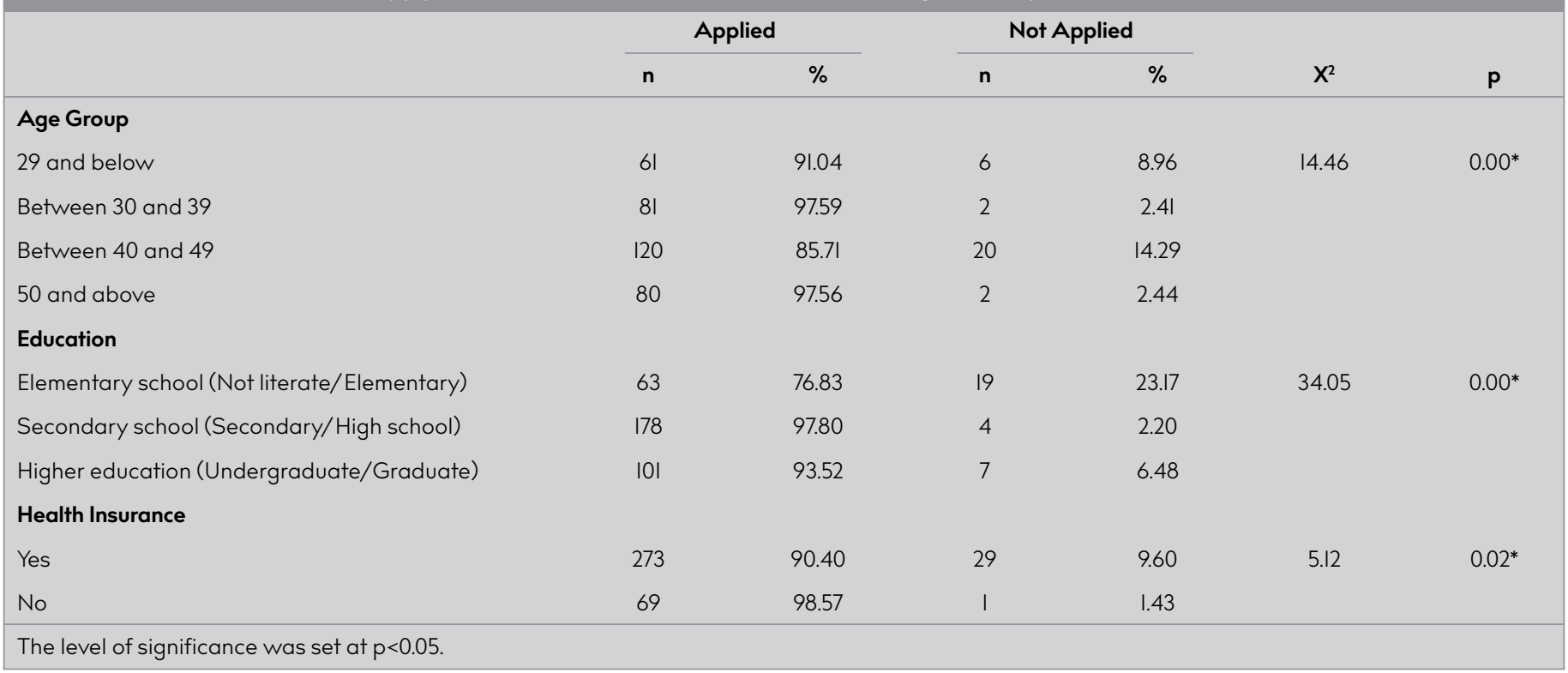


TABLE 2. The statistics of women who apply a traditional method on their babies, according to some descriptive characteristics ( $\mathrm{n}: 372$ )

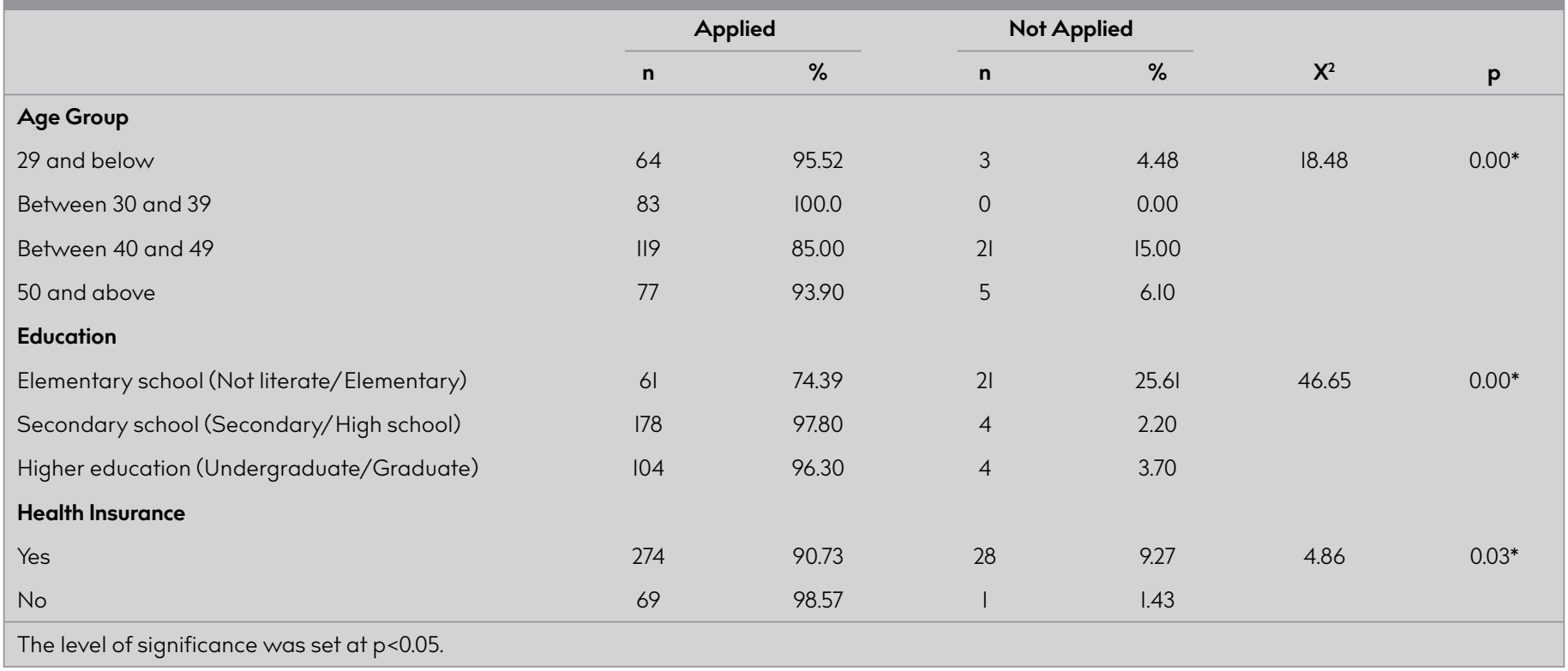

\begin{tabular}{|c|c|c|}
\hline \multirow[b]{2}{*}{ Practices } & \multicolumn{2}{|c|}{ Statistics of Knowing } \\
\hline & Number $(n)$ & Percentile (\%) \\
\hline For the puerpera & 372 & 100 \\
\hline Postpartum hemorrhage & 194 & 52 \\
\hline Increasing lactation of the puerpera & 372 & 100 \\
\hline Decreased lactation of the puerpera & 253 & 68 \\
\hline Preventing albasması & 356 & 96 \\
\hline Healing albasması & 286 & 77 \\
\hline
\end{tabular}

According to the demographic characteristics of the women, the results of applying traditional practices in the postpartum period are presented in Table l, and the results for infants are presented in Table 2. A statistically significant difference was found between the age groups of women, their educational status, their health status, and the practice of traditional method in the postpartum period $(p<0.05)$. No statistically significant difference was found between the application of traditional practices and respondents' economic situation ( $p>0.05)$. The frequency of traditional method practices in women who were in the age group between 40 and 49 years with the primary school education level and who had health insurance was lower than that of women who were either above 50 or under 40 years of age, completed secondary school or higher education, and had no health insurance.

Table 3 represents the situations where women knew at least one traditional practice for maternity care. It was found that all women knew at least one traditional practice for maternity care and increasing lactation. Regarding traditional practices for postpartum hemorrhage (52\%), decreased lactation (68\%), prevention of albasması (a local belief suggesting that the woman can show the symptoms of febrility, somniloquy, and hallucination because of the influence of bad spirits in the postpartum period) (96\%) and healing of albasması (77\%).
TABLE 4. Distribution of traditional practices applied by women for maternal care (n:372)

\begin{tabular}{lcc} 
Practices & $\mathbf{n}$ & $\%$ \\
\hline Blessing the fortieth day of the puerpera & 295 & 79.30 \\
No sexual intercourse for 40 days for the puerpera & 250 & 67.20 \\
Not letting women who are having their period get & 165 & 44.35
\end{tabular}
near the puerpera

For woman with postpartum hemorrhage

Raising puerpera's feet

$71 \quad 36.60$

Suppressing puerpera's abdomen

$62 \quad 31.96$

For increasing the lactation

Making puerpera eat sweet

Making puerpera eat onion

$320 \quad 86.02$

In case of decreased lactation

Letting the mother eat whatever she craves for $\quad \begin{array}{lll}792 & 75.89\end{array}$

Applying steam to breasts

$69 \quad 27.27$

For preventing the albasması of the puerpera

Placing Quran in the room where the puerpera rests $\quad \begin{array}{lll}240 & 67.426\end{array}$

Not leaving the puerpera alone in the house

$235 \quad 6.01$

For healing the albasması of the puerpera

Praying

$81 \quad 28.322$

Having the puerpera take a bath for blessing on the fortieth day

$71 \quad 4.83$

More than one answer was given. Percentages were taken over the number of women who knew at least one traditional practice for the puerperal woman.

The traditional practices for women during the postpartum period are shown in Table 4. Among these practices, the blessing of the fortieth day of the postpartum period (79.3\%), not having sexual intercourse for 40 days (67.2\%), and not letting women who are having their period to get near the puerperal women (44.35\%) were the practices in general. When asked what they 
would do with the puerperal woman who has postpartum hemorrhage, $36.6 \%$ said that they would raise her feet, and $31.96 \%$ stated that they would suppress her abdomen. While $86.02 \%$ of the women would make sure that the mother consumed plenty of fluids, $72.85 \%$ of them suggested that the mother should have sweet foods, and $59.95 \%$ of them would advise mothers to eat onions to increase the lactation; $75.89 \%$ claimed that the mothers should eat whatever they crave for, and $27.27 \%$ said that they would apply steam to the breasts if the lactation would decrease. Placing Quran in the room where the puerperal woman rests $(67.42 \%)$ and not leaving her alone in the house $(66.01 \%)$ were among the traditional practices to prevent the albasmasl. However, to heal the albasmas, it was reported that $28.32 \%$ of the women would pray, and $24.83 \%$ of them suggested that the mother should have a bath for blessing on the fortieth day of the postpartum period.

The results of women who knew at least one traditional practice for the newborn or infant care is reported in Table 5 . It was found that all women knew at least one traditional practice for newborns and babies. The practices of protecting the baby from the evil eye (100\%), preventing jaundice (99\%), the first baby bath (94\%), and the first feeding of the baby (93\%) were the top ones among the practices that women expressed they knew.

Table 6 shows the traditional practices that women apply to newborns and babies in the postpartum period. A total of $77.69 \%$ of the women celebrated the fortieth day, and $40.32 \%$ of them swaddled their babies. For the first feeding of the newborns, $46.82 \%$ of the women gave the newborn sugar water as the first nutrient. $48.29 \%$ said that they bathed the newborn after the baby's umbilical cord fell off, $43.36 \%$ of them used olive oil for the baby's umbilical cord to make it fall off quicker, and $26.58 \%$ of them buried the baby's umbilical cord in the school

\begin{tabular}{lcc|}
\hline TABLE 5. The statistics of women who knew at least one traditional \\
practice to apply in the newborn and infant care (n:372) \\
\cline { 2 - 3 } Practices & \multicolumn{2}{c|}{ Statistics of Knowing } \\
\cline { 2 - 3 } Number ( $\mathrm{n})$ & Percentile (\%) \\
\hline For the newborn and baby & 372 & 100 \\
First feeding & 346 & 93 \\
First bath & 350 & 94 \\
For the umbilical cord to fall off quicker & 286 & 77 \\
After the umbilical cord falls off & 301 & 81 \\
Not to develop jaundice & 368 & 99 \\
In case of jaundice & 324 & 79 \\
Protecting from the evil eye & 372 & 100 \\
When touched by the evil eye & 338 & 91 \\
For the baby to be beautiful & 275 & 74 \\
In case of candidiasis & 246 & 60 \\
In case of neonatal dermatitis & 324 & 87 \\
In case of rash & 353 & 95 \\
In case of gas pain/ bloating & 372 & 100 \\
In case of diarrhea & 352 & 95 \\
In case of fever & 372 & 100 \\
\hline
\end{tabular}

\section{TABLE 6. Distribution of traditional prac the newborn and infant care (n:372)}

\section{Practices}

Blessing the fortieth day

n 289

Swaddling

For the first feeding of newborn

Giving the newborn sugar water as the first nutrient

Giving the newborn formula food as the first nutrient

For the first bath of newborn

After the newborn's umbilical cord falls off

Before the newborn's umbilical cord falls off

For the newborn's umbilical cord to fall off quicker

Applying olive oil on the belly

Wiping with alcohol

After the newborn's umbilical cord falls off

Burying it in the school garden

Burying it in the house garden

For the newborn not to develop jaundice

Breastfeeding/Feeding

Tying yellow cloth or gauze

Having the newborn sunbathe for 40 days

For the newborn in case of jaundice

Breastfeeding/Feeding

Having the newborn sunbathe

Tying yellow cloth or gauze

To protect the baby from evil eye

Pinning an amulet (blue bead) on clothes

Praying

For the baby when touched by the evil eye

Pouring lead

Having an elderly person or a Muslim preacher to pray

For the baby to be beautiful

Pinching nose

Applying pressure to cheeks and the jaw

For the newborn in case of candidiasis

Wiping mouth with dry cloth

Applying baking soda in the mouth

For the newborn in case of neonatal seborrheic dermatit

Applying olive oil on the head

Combing baby's hair with a thin brush

For the newborn in case of rash

Applying cream

Applying powder

For the newborn in case of gas pain

Massaging belly with olive oil

Feeding with anise tea

For the newborn in case of diarrhea

Giving plenty of water

Feeding with rice and yogurt

For the newborn in case of fever

Taking off the baby's clothes

Warm bath/warm application

Wiping with vinegar diluted with water

More than one answer was given. Percentages were taken over the number of women who knew at least one traditional practice for the newborn and infant care. 
garden. Regarding preventing the newborn baby from developing jaundice, women stated that they tied yellow cloth, $75.54 \%$ of them while breastfeeding and $70.92 \%$ of them directly to the bed. In case of jaundice, $75.62 \%$ of the women breastfed, and $64.2 \%$ of them let the newborn sunbathe. To protect the baby from evil spirits, $93.01 \%$ of the women were wearing blue beads, and $76.88 \%$ were praying; and if it was believed that the baby was touched by the evil eye, $44.97 \%$ poured lead (a ritual of pouring molten lead from one pot to another pot held above a baby's head to keep the evil eye away), and $26.63 \%$ requested an elderly person or a Muslim preacher to pray. $44.36 \%$ of the women expressed that they pinched the baby's nose to make the baby beautiful, $32.39 \%$ of them wiped the mouth of the newborn with a dry piece of cloth if the baby had candidiasis, and $68.21 \%$ said that if the baby had honeycomb disease, they rubbed some olive oil onto the head of the newborn. In case of rash, $88.39 \%$ of the women chose to rub the rash with a cream, in case of gas pains (bloating), $88.17 \%$ of them rubbed the newborn's stomach with olive oil, and in case of diarrhea, $70.17 \%$ of them gave plenty of water to the babies. In case of fever, giving a warm bath (95.43\%) and taking the clothes off $(94.09 \%)$ were among the most frequent practices that the women applied.

\section{DISCUSSION}

It was observed that most of the women in the study knew and applied traditional practices for the maternal and infant care in the postpartum period. These included practices that might be both useful and harmful to the mother or the baby.

The practice of "not allowing sexual intercourse for 40 days" is one of the useful practices. This method is also applied in Turkey. A review of the literature showed that this method was also being applied in different cities of Turkey $(3,7)$. In fact, this practice of "not allowing sexual intercourse for 40 days" can be considered as a beneficial practice because it is supported by modern medicine in the sense that the puerperal woman who is sensitive to the infections in this period due to lacerations or episiotomy that occur during labor feels pain during sex (7).

Hemorrhage that occurs in the postpartum period is one of the leading causes of maternal deaths in Turkey (II). Any kind of traditional practice during bleeding can put women's health and life under risk. Studies in the literature showed that there were many traditional applications for the postpartum period $(7,12)$. In our study, it was determined that women applied the methods of "raising the puerpera's feet" and "suppressing the puerpera's abdomen" in cases of postpartum hemorrhage. Suppressing the puerpera's abdomen is an application that can save lives when done correctly. However, only educated health care staff can do this most accurately and can provide a medical follow-up. Women should be informed about reporting to a health institution in case of bleeding, as soon as possible before resorting to any traditional practice.

"The puerpera's consuming plenty of fluids" is a useful practice for increasing the lactation. In case of decreased lactation, "letting the puerperal woman eat whatever she craves" may be considered harmful in case of an excessive calorie intake. In the study by Lafçı and Erdem (12), it was found that the most commonly used method for increasing lactation was to eat molasses or halva with 68\%, and in the study by Gölbașı and Eğri
(7), it was found that it was preferred for puerperal woman to consume watery foods with a maximum of $71.3 \%$. In the first 6 months, mothers should only breastfeed their babies, and the most important reason for the early start of additional meals is inadequate lactation. For adequate milk production, it can be said that these practices are beneficial, given that the puerperal woman should consume at least 3 liters of fluid per day, and 500 calories per day should be added to her diet. However, an excessive consumption of sweet foods or caloric intake can lead women to gain weight $(7,13)$.

For preventing the albasması, practices such as "not leaving the puerperal woman alone in the house" and "placing Quran in the room where the puerperal woman rests"; and for healing the albasması, practices such as "having puerperal woman take a bath on the fortieth day" and "praying" are the practices that can be considered beneficial since they relieve the mother psychologically. It draws attention that in order to prevent the albasması, the most used method in Gölbașı and Eğri's (7) work was "placing things in the room where the puerperal woman rests" (bread, scissors, broom, Quran) with 89.4\%, and in Lafçı and Erdem's (12) work, the same practice was also on top with $48 \%$.

Koyun et al. (14) found that the practice of "placing a cutting, drilling tool under the cushion of the puerpera" was $22 \%$, while Ișık et al. (I3) stated that "not letting the puerperal woman out of the house for 40 days" was the top practice regarding the albasması belief in their study. When the survey results were evaluated, in our district and in various regions of Turkey, we saw that these practices were still being widely applied. These practices have no harm to the mother and are considered useful psychologically. However, there is a health problem at the root of the situation that is believed to be albasması colloquially. It can be maternal sadness, postpartum depression, infection, or dehydration $(7,15)$. Applying traditional methods with the belief of albasması may cause the health condition of the puerperal woman to get worse by delaying the treatment.

In the postpartum period, breastfeeding is found to be one of the beneficial traditional practices applied for the newborn not to develop jaundice. "Yellow cover or tying gauze" method can also be considered as a psychologically beneficial practice without direct harm to the baby. However, in case of jaundice, this may be harmful since it may delay diagnosis and treatment. Covering the newborn's face with yellow gauze was the most used practice with $55.3 \%$ in Yalçın's (16) work, which he conducted in Karaman, and with 84\% in Lafçı and Erdem's (12) work. In the study by Arisoy et al. (6), it was determined that the most frequently used method for keeping the newborn from developing jaundice was frequent feeding, at $78.5 \%$. Traditional practices for the prevention of jaundice in newborn babies have generally no adverse effects on baby's health $(I, 13)$. Feeding with breast milk have great importance in preventing jaundice. For this reason, breastfeeding the newborn is effective in avoiding jaundice. Nurses should train parents to breastfeed after birth and should make them aware of the effect of this behavior on physiological jaundice.

"Applying olive oil on newborn's head" in case of neonatal seborrheic dermatitis, "rubbing the newborn's belly with olive oil" in 
case of gas pains (bloating) are beneficial practices supported by modern medicine, whereas "applying olive oil on the belly" for baby's umbilical cord to fall off quicker is a harmful practice. In both the studies conducted by Çınar et al. (17) and Çalıșkan and Bayat (18), women also stated that they used olive oil for neonatal seborrheic dermatitis. C. Inar et al. (17) identified that in order to relieve the gas pain, the methods such as massaging (50.8\%) and making newborn drink some olive oil (9.2\%) were used. In Uğurlu et al.'s (19) study, making newborn drink herbal tea was found in $21.3 \%$ of cases. Because of the gas problem, abdominal pain is a common condition in infants. Modern medicine supports the application of olive oil, and massage is an effective application to alleviate the gas problem and symptoms. But since olive oil is not sterile, it is inconvenient and harmful to apply olive oil on the belly for baby's umbilical cord to fall off quicker. Non-sterile or dirty items placed on the umbilicus may cause tetanus or infections leading to infant's sepsis deaths (6, $7,13)$.

Furthermore, it was found that the women included in the study made the newborn drink plenty of water in case of diarrhea. In the study by Bölükbaș et al. (10), the percentage of "giving the newborn plenty of water to drink" was found to be $26.6 \%$. In the study by Çınar et al. (17), we saw breastfeeding at $14.3 \%$, and "giving the newborn plenty of water to drink" at 13.2\%. Other study results are similar to our results. Decreased body fluids with diarrhea can cause dehydration of the baby, resulting in many complications or even death (20). In case of diarrhea, it is a pleasing situation that the mothers do not restrict the fluid, and on the contrary, the fact that they increase the amount of fluid is a useful application.

In this study, among the traditional methods applied in the newborn and baby in the postpartum period, "blessing the fortieth day" and the practices applied after the newborn's umbilical cord fell off were not harmful to baby's health and were found to be psychologically relaxing for the family.

There are no direct injuries to newborns or babies when it comes to the practices aiming to protect from the evil eye or the ones done when the newborn or baby is believed to be touched by the evil eye. However, the interpretation of the actual disease symptoms as an evil eye and resorting to various traditional practices instead of reporting to a health institution may have negative consequences for the health of the baby. The study results are parallel to our study $(1,12)$.

The practices of "swaddling" and "giving sweetened water" as the first food to newborn are the unhealthy traditions which stand out in our work. The tradition of swaddling is a common practice in Turkish society. The swaddled baby will be uncomfortable, restless, and prone to hip dislocation (I, 2). For this reason, we can say that swaddling affects the health of the baby adversely. In the literature, it can be found that it is possible to prevent newborn complications by breastfeeding and early breastfeeding within the first 30 minutes after birth $(21,22)$. So, raising mothers' awareness about baby care may be effective in reducing harmful traditional practices.

The discussion part has been done with a limited number of studies from the literature because, to the best of our knowl- edge, there are no studies previously conducted in Cyprus covering this topic.

Finally, in the direction of our findings, it was determined that there were traditional methods known or applied by the women living in the center of Nicosia for maternal and infant care in the postpartum period. As the traditional methods applied in the postpartum period are being evaluated by nurses, cultural differences should be taken into consideration, the situations should not be handled by judgmental behaviors, maternal education about the harmful practices should be provided, and harmless or beneficial traditional practices should be supported.

Ethics Committee Approval: Ethics committee approval was received for this study from Near East University (Approval Date: 17.19.2015, Approval Number: YDÜ/2015/32-222).

Informed Consent: Informed consent was obtained from the patients who participated in this study.

Peer-review: Externally peer-reviewed.

Author contributions: Concept - D.N., B.K.; Design - D.N., B.K.; Supervision - D.N., B.K.; Resource - D.N., B.K.; Materials - D.N., B.K.; Data Collection and/or Processing - D.N.; Analysis and/or Interpretation - D.N., B.K.; Literature Search - D.N., B.K.; Writing Manuscript - D.N., B.K.; Critical Reviews - D.N., B.K.

Conflict of Interest: The authors have no conflicts of interest to declare.

Financial Disclosure: The authors declared that this study has received no financial support.

\section{REFERENCES}

I. Eğri G, Gölbașı Z. Traditional Methods Married Women Apply to their Babies during the Postnatal Period According to Age Group. Preventive Med Bul 2007; 6: 3/3-20.

2. Çelik SA, Çapık A, Engin R. Determination of Traditional Practices in Pregnancy and Postpartum Period in Erzurum. Anatolian $\mathrm{J}$ of Nurs and Health Sci 2012; 15: 262-7.

3. Cetișli EN, Muslu KG, Șen S, Güneri ES, Bolıșık B, Saruhan A. Traditional Practices in Postnatal Period in Aegean Region. J of Int Refereed Nurs Res 20l4; 2: 22-35.

4. Eğri G, Konak A. Examples from the World and Turkey for Traditional Beliefs and Practices Related to the Postpartum Period. J of World of Turks 2011; 3: 143-55.

5. Vargün B. Traditional Methods for the Protection of Mother and Baby During Birth and After Birth. J of Human Sciences 2018; 15: 87080. [CrossRef]

6. Arisoy A, Canbulat N, Ayhan F. Traditional Methods Applied by Mothers in Baby Care in Karaman Province. Anatolian $\mathrm{J}$ of Nurs and Health Sci 2014; 14: 23-31.

7. Gölbașı Z, Eğri G. Traditional Practices for Nursing of the Mother During the Postnatal Period. Cumhuriyet Med J 2010; 32: 276-82.

8. Karahan N, Aydın R, Güven YD, Benli AR, Kalkan NB. Traditional Health Practices Concerning Pregnancy, Birth and the Postpartum Period of Women Giving Birth in the Hospital. J of South Clin Ist Euras 2017; 28: 190-8.

9. Bayram $\vee$, Deveci ES. The Evaluation of the Known and/or Applied Traditional Methods in Mother Care During Postpartum Period Among Married Women Living in Kızltepe, Mardin Province. Firat Med J 2017; 22: 34-42.

10. Bölükbaș N, Erbil N, Altuntaș H, Arslan Z. Traditional Practices of 0-12 Months Baby Care Mothers Applying for Child Care. Inter J of Human Sci 2009; 6: 164-76. 
II. Turkish Statistical Institute, 2018. (Date Accessed: 10 September 20l8). http://www.tuik.gov.tr/PreTablo.do?alt_id=1083.

12. Lafç $D$, Erdem E. Traditional Practices Regarding Mother and Infant Care of I5-49 Year Old Married Women in the Postpartum Period. Gaziantep Med J 2014; 20: 226-36. [CrossRef]

13. Ișık T, Akçınar M, Kadıoğlu, S. Traditional Practices Applied to Mother and Newborn during Pregnancy, Birth, and Postpartum Periods in Mersin. Inter J of Human Sci 2010; 7: 63-84.

14. Koyun A, Çamuroğlu C, Korkmaz G, Menteșe N, Ocak F. Beliefs and Practices of Women on Pregnancy, Birth and Newborn Care. Journal of Social Policy Studies 2010; 6: 57-64

15. Bakır E, İnci H, Alan S, Gökyıldız Ș, Elmas E. Belief About Puerperal Fever and Traditional Practices in Adana. Lokman Hekim J 20II; I: $13-8$

16. Yalçın H. Traditional Practices Related to Pregnancy, Birth, Puerperium and Baby Care; Karaman Example. J of Child Health and Diseases 2012; 55: 19-31.
17. Çınar Öi, Aslan KG, Kartal A, İnci HF, Koștu N. Investigation of Traditional Methods Applied by Mothers To 0-I Age Babies. TAF Prev Med Bul 20l5; 14: 378-86.

18. Calișkan Z, Bayat M. Infant Care Practices and Affecting Factors: An Example of Cappadocia. Anatolian J of Nurs and Health Sci 20II; 14: 24-30.

19. Uğurlu SE, Bașbakkal Z, Dayılar H, Çoban V, Ada Z. Investigation of Traditional Methods Applied by Mothers for Infant Care in Ödemiș. Gumushane Univ J of Health Sci 2013; 2: 342-60.

20. Șanlier N, Aytekin F. 2004. Analysis of Knowledge Level Behavior of Mothers with Children of 0-3 years of Age Concerning Nutrition and Diarrhea. J of Gazi Univ Fac of Edu 2004; 24: 8I-100.

21. Yiğitalp G, Gümüș F. Traditional İnfant Care Practices of Women Aged 15-49 in Diyarbakır. Turkish J of Pediatr Dis 2017; II: 188-96.

22. Sivri BB, Karataș N. The Cultural Direction of Society: Traditional Practices and Examples from the World for Mother and Baby Care in the Postnatal Period. J Curr Pediatr 2015; 13: 183-93. 